\title{
¿QUÉ SON LAS COMPETENCIAS EN EDUCACIÓN? UNA APROXIMACIÓN DESDE EL ENFOQUE SOCIOFORMATIVO
}

\section{Nicte de Fátima Guajardo Concha ${ }^{1}$}

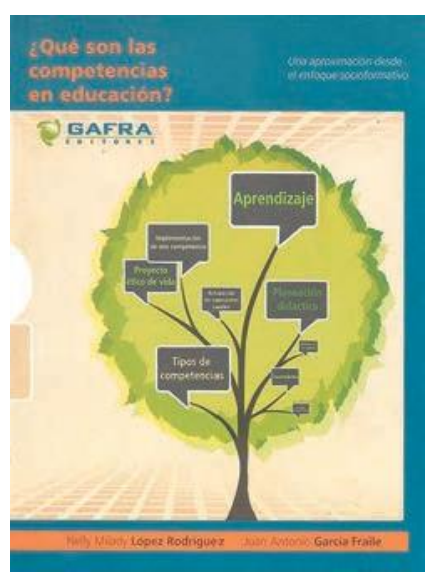

Inicio la reseña de este libro, compartiendo la denición de competencia. Éstas son entendidas como los conocimientos, habilidades y destrezas que desarrolla una persona para comprender, transformar y participar en su entorno. Las competencias no son una novedad en el ámbito educativo. Desde hace algunos años se viene hablando de este tema, y ha sido el propio Ministerio de Educación Nacional quien ha fortalecido este cambio con la única intención de que realmente exista un cambio en las concepciones de todo el que se halla inmerso en la educación.

Es necesario aclarar que existen diversos enfoques para entender que son las competencias, los autores de este libro han fundamentado toda su trayectoria investigativa es uno de ellos, nos referimos al enfoque socioformativo, el cual articula las competencias con el pensamiento complejo, la investigación acción educativa y la gestión de la calidad educativa, lo que permitirá la aplicación de diversas estrategias didácticas, así como realizar una evaluación por competencias, la cual toma en cuenta los criterios y las evidencias, todo esto con miras de realizar una verdadera educación integral de los estudiantes.

En el primer capítulo "Las competencias: concepto, tipos y retos para el educador", la intención de los autores es realizar una explicación con-

1 Profesora del Centro de Estudios en Educación y miembro de ESPIRAL-Grupo Interdisciplinario Educativa de la Universidad Santo Tomás, Bucaramanga. ceptual de los diversos enfoques (funcionalista, conductual, constructivista y socioformativo) que abordan el término competencias, partiendo de que éstas son la base para la calidad educativa. El término de competencias proviene del latín competere que signica lo que corresponde a la persona hacer con responsabilidad e idoneidad en un área y del griego agon y agonistes que quiere decir rivalizar con competición o competitividad, por último en este primer capítulo se hace mención de las diversas concepciones sobre competencias en las áreas disciplinares, así como los aportes que los ámbitos cientícos le han dado a este concepto.

Los autores ofrecen en el segundo capítulo "Las competencias: un enfoque socioformativo", una explicación amplia de lo que comprende el término de competencias desde el enfoque socioformativo, el cual permite la formación humana integral como un proyecto ético de vida, tomando en cuenta diversos desempeños, contextos, integración de saberes así como la idoneidad. Cuatro saberes son esenciales en la formación por competencias nos referimos a saber ser, saber convivir, saber conocer y saber hacer; en su conjunto se permite como ya mencionamos la formación integral debido a que toma en cuenta las siguientes dimensiones:

- Dimensión cognitiva: conocimientos, conceptos y habilidades cognitivas

- Dimensión socio-afectiva: actitudes y valores

- Dimensión actuacional: habilidades, procedimientos y técnicas.

Por lo anterior se considera que las competencias desde este enfoque son algo más que 
un simplemente saber hacer, yendo esto muy de la mano con el pensamiento complejo propuesto por Edgar Morin.

Para la construcción de una competencia son dos los pasos que se deben seguir, en un primer momento se requiere efectuar la identicación de la competencia a partir del contexto, esto se hace a través de verbo de desempeño (se dene tomando en cuenta el nivel de desarrollo de pensamiento que tiene el estudiante), objeto conceptual (son los elementos teóricos a formar), nalidad (el para que se van a formar los elementos teóricos) y condición de referencia (se toman en cuenta los criterios, códigos éticos, normativos, referentes y contextos que sirven para fundamentar los elementos teóricos); en segundo lugar se debe realizar la descripción de criterios y evidencias; los primeros se reeren a las pautas de valoración de los saberes de la competencia y las evidencias son las pruebas concretas del logro de la competencia y nos permite vericar los criterios, estos dos últimos elementos serán de gran utilidad al momento de efectuar la evaluación por competencias, la cual se efectúa a través de las matrices de evaluación para lo cual es indispensable denir los niveles de desarrollo o dominio de la competencia, los autores han establecido 5 niveles, estos son, nulo, inicial-receptivo, básico, autónomo y estratégico; cada uno de ellos tiene unas características especícas que permiten comprobar la adquisición del aprendizaje por parte del estudiante.

Se considera importante mencionar que existen tres clases de competencias, las cuales son: competencias básicas, competencias genéricas o transversales y competencias especícas, todas ellas en su conjunto buscan formar de manera integral tomando en cuenta los saberes esenciales ya mencionados.
Finalmente los autores nos ofrecen algunas de las críticas más frecuentes que se le han hecho a la formación por competencias, algunas de ellas se reeren a que las competencias no existen o que son una moda, estas críticas son bien recibidas pero el enfoque socioformativo muestra que apoyado en la literatura existente que las competencias son construcciones teóricas e integradoras que representan las diversas dimensiones del desempeño idóneo ante actividades y problemas del contexto en el que se encuentra involucrado el estudiante.

Por último se podrá encontrar al nal de la obra un glosario que contiene los conceptos esenciales y que ayuda a claricar un poco más que son las competencias desde en el enfoque socioformativo.

\section{Reseña:}

López Rodríguez, Nelly Milady y García Fraile, Juan Antonio (2012). ¿Qué son las competencias en educación? Una aproximación desde el enfoque socioformativo, Gafra Editores, México. 
